\section{International Scientific Journal Theoretical \& Applied Science}

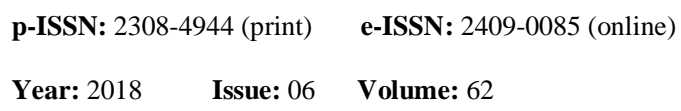

SECTION 9. Chemistry and chemical technology.
Elena Petrovna Pyshkova Assistant of the Department of Occupational Health and Environmental Safety, Ukrainian Engineering and Pedagogical Academy, Ukraine lenpushkova@gmail.com

Pavel Aleksandrovich Dmitriev Assistant of the Department of Occupational Health and Environmental Safety, Ukrainian Engineering and Pedagogical Academy, Ukraine dmitrievpavelaleksandrovich@ukr.net

Aleksandr Nikolaevich Baklanov Doctor of chemical sciences, Professor, Head of the Department of Occupational Health and Environmental Safety, Ukrainian Engineering and Pedagogical Academy, Ukraine baklanov_oleksandr@meta.ua

Larisa Vladimirovna Baklanova Candidate of chemical sciences, Docent, Associate Professor of the Department of Occupational Health and Environmental Safety, Ukrainian Engineering and Pedagogical Academy, Ukraine baklanovalarisa@ukr.net

\title{
IMPROVING THE SAFETY OF THE SALT. CONTENT DETERMINATION VARIOUS FORMS OF CHROM
}

\footnotetext{
Abstract: The use of ultrasound for the intensification of sample preparation in the spectrophotometric determination of chromium in common salt and brines is studied: to remove carbon dioxide from the analyzed solutions, to intensify the concentration of chromium (III) by coprecipitation, to oxidize chromium (III) to chromium (VI). A procedure for the determination of chromium (III) and chromium (VI) in common salt and brines has been developed. The limit of detection of chromium in the photometry of aqueous solutions of diphenylcarbazide $0.012 \mathrm{mg} / \mathrm{kg}$, when extracting the chromium (VI) complex with diphenylcarbazide in isoamyl alcohol is $0020 \mathrm{mg} / \mathrm{kg}$.

Key words: ultrasound, table salt, safety, chromium in various degrees of oxidation.

Language: Russian

Citation: Pyshkova EP, Dmitriev PA, Baklanov AN, Baklanova LV (2018) IMPROVING THE SAFETY OF THE SALT. CONTENT DETERMINATION VARIOUS FORMS OF CHROM. ISJ Theoretical \& Applied Science, 06 (62): 31-37.

Soi: http://s-o-i.org/1.1/TAS-06-62-7 Doi: crossef https://dx.doi.org/10.15863/TAS.2018.06.62.7

\section{ПОВЫШЕНИЕ БЕЗОПАСНОСТИ ПОВАРЕННОЙ СОЛИ. СПЕКТРОФОТОМЕТРИЧЕСКОЕ ОПРЕДЕЛЕНИЕ ХРОМА}

Аннотация: Изучено использование ультразвука для интенсификации пробоподготовки при спектрофотометрическом определении хрома в поваренной соли и рассолах: для удаления углекислоты из анализируемых растворов, для интенсификации конщентрирования хрома (III) соосаждением, для окисления хрома (III) до хрома (VI). Разработана методика определения хрома (III) и хрома (VI) в поваренной соли и рассолах. Предел обнаружения хрома при фотометрировании водных растворов дифенилкарбазида 0,012 мг/кг, при экстрагировании комплекса хрома(VI) с дифенилкарбазидом в изоамиловый спирт -0,0020 мг/кг.
} 
Ключевые слова: ультразвук, поваренная соль, безопасность, хром в различных степенях окисления

\section{Введение.}

Токсичность хрома зависит от формы его существования, так предельно допустимое содержание хрома (III) в питьевой воде 0,5 мг/дм ${ }^{3}$, хрома (VI) - 0,1 мг/дм ${ }^{3} \quad[1,2]$. В связи с введением хрома в число нормируемых токсичных элементов, подлежащих обязательному контролю в продуктах питания, возникла необходимость контроля содержания хрома в поваренной соли, являющейся одним из пищевых продуктов [2]. Фоновое содержание хрома и форма его существования в месторождениях пищевой поваренной соли стран СНГ изучены недостаточно.

Нами предложен атомно-абсорбционный метод определения хрома, включающий разрушение органических соединений хрома, его экстракцию в виде ацетилацетоната в хлороформ с последующей реэкстракцией и распылением реэкстракта в пламя горелки спектрометра. Причем для ускорения синтеза ацетилацетона и для разрушения органических соединений хрома был использован ультразвук (УЗ), что позволило повысить экс пресность анализа [3]. Однако, лаборатории солепредприятий стран СНГ в основном ориентируются на спектрофотометрию и оснащены спектрофотометрами [4].

Для определения хрома в водах наибольшее распространение получил спектрофотометрический метод основанный на соосаждении хрома (III) с гидроксидом титана(IV) или магния с последующим окислением до хрома(YI) и определением с дифенилкарбазидом при 535 нм [5, 6]. Однако, степень соосаждения хрома (III) не превышает 92 $\%$ и ее не удается повысить увеличением количества коллектора [5]. Для окисления хрома(III) до хрома (VI) используют кипячение проб с персульфатом аммония в кислой среде или с гипохлоритом натрия в слабощелочной, а поскольку избыток окислителей мешает дальнейшему определению хрома (VI), то их разрушение требует кипячения анализируемых растворов в течение 30-45 мин, что усложняет и удлиняет анализ $[5,6]$.

Раннее нами было предложено использование ультразвука (УЗ) для ускорения процессов пробоподготовки при определении токсичных и биоактивных элементов в пищевых продуктах. Экспрессность анализа повысилась в 5-10 раз [7-9].

Предлагаемая работа посвящена изучению использования УЗ при спектрофотометрическом определении общего хрома, хрома (III) и хрома (VI) в рассолах и поваренной соли.

\section{Экспериментальная часть.}

Определение хрома проводили с использованием спектрофотометра СФ-46 (Россия). Ультразвуковую обработку растворов осуществляли с помощью модернизированного У3 диспергатора УЗДН-1V, позволяющего изменять частоты ультразвука от 15 до 47 кГц с регулировкой интенсивности от 0,5 до $25 \mathrm{BT} / \mathrm{cm}^{2}$ [5]. Интенсивность УЗ определяли расчетным и экспериментальным методами с использованием ультразвуковых торзионных весов ИМУ-3 и ультразвукового анализатора скорости УЗАС - 7 [1]. Результаты определения интенсивности УЗ двумя вышеприведеными методами оказались достаточно близкими. Измерение величины $\mathrm{pH}$ растворов соли проводили с помощью рН-метра pH 673 М или иономера ЭВ - 74 со стеклянным индикаторным электродом ЭСП-14-01. Применяли бидистиллированную воду, полученную перегонкой в кварцевом приборе. Соляную кислоту и аммиак очищали изотермической дистилляцией [1]. Остальные реактивы, квалификации не ниже х.ч., использовали без дополнительной очистки. В качестве головного стандарта использовали государственный стандартный образец хрома ГСО 5236-90 производства физико-химического института им.Богатского (г. Одесса).

Методика эксперимента.3232 Применение гидроксида магния в качестве коллектора для соосаждения хрома(III) из растворов поваренной соли обусловлено тем, что магний является основной примесью поваренной соли [5]. Это позволяет избежать необходимости введения дополнительного реагента и в связи с чем, уменьшить риск загрязнения анализируемой пробы хромом из используемых реагентов. В химические стаканы помещали по 1000 мл раствора хлорида натрия (от 50 до 200 г/л), подкисляли раствор 2 мл соляной кислоты и кипятили в течение 10 мин для удаления углекислоты [5]. Приливали определённые количества растворов хрома (III) и магния. Добавлением раствора гидроксида натрия устанавливали $\mathrm{pH}$ более 10,5, т.к. при таком pH исключается соосаждение хрома (VI) [5]. Полученную смесь встряхивали в течение выбранного времени. После отстаивания, жидкость сливали сифонированием и отделяли осадок от остатков раствора центрифугированием. Осадок растворяли в серной кислоте (1:5). Для окисления хрома (III) до хрома (VI)) использовали обработку проб персульфатом аммония в кислой среде или гипохлоритом натрия, избыток окислителей разрушали кипячением в течение 30-45 мин [5, 6]. В полученном концентрате устанавливали 
содержание хрома спектрофотометрическим методом с дифенилкарбазидом при 535 нм [6]. Также проводили пробоподготовку тех же проб с использованием УЗ для удаления углекислоты, для интенсификации концентрирования хрома(III) соосаждением с гидроксидом магния, для разрушения остаточных количеств гипохлорита натрия и удаления хлора. Опыты с использованием УЗ проводидили при постоянной температуре $(20 \pm 1) \quad 33^{\circ} \mathrm{C} \quad$ [9]. Содержание примесей хрома в используемых реактивах учитывали с помощью холостого опыта.

\section{Результаты и обсуждение.}

Оптимальными условиями соосаждения хрома (III) были следующие: количество осадка коллектора не менее 6 ммоль/л, концентрация хлорида натрия не более 100 г/л, $\mathrm{pH}$ раствора 10,5-13,0 время контакта осадка с раствором не менее 5 мин (табл.1). При повышении температуры, в отсутствии встряхивания степень соосаждения хрома повышается (табл. 1).

Влияние концентрации хлорида натрия, количества коллектора (КК), рН раствора, времени контакта осадка с раствором и температуры на степень соосаждения (CC) хрома(III) с гидроксидом магния

\begin{tabular}{|c|c|c|c|c|c|c|c|c|c|}
\hline $\begin{array}{c}\text { Концентрация } \\
\text { NaСI, г/л }\end{array}$ & $\begin{array}{c}\text { СС, } \\
\boldsymbol{\%}\end{array}$ & $\begin{array}{c}\text { КК, } \\
\text { моль/л }\end{array}$ & $\mathbf{C C , ~ \% ~}$ & $\mathbf{p H}$ & $\mathbf{C C , ~ \% ~}$ & $\begin{array}{c}\text { Время, } \\
\text { мин }\end{array}$ & $\mathbf{C C , ~ \% ~}$ & $\begin{array}{c}\text { *Темпе- } \\
\text { ратура, } \\
\mathbf{0}\end{array}$ & $\mathbf{C C , ~ \% ~}$ \\
\hline 40 & 92 & 2 & 45 & 10,5 & 92 & 2 & 51 & 40 & 43 \\
\hline 50 & 92 & 3 & 59 & 11,0 & 92 & 3 & 79 & 50 & 62 \\
\hline 70 & 92 & 4 & 65 & 11,5 & 02 & 4 & 90 & 60 & 69 \\
\hline 100 & 92 & 5 & 92 & 12,0 & 92 & 5 & 92 & 70 & 78 \\
\hline 110 & 89 & 6 & 92 & 12,5 & 92 & 6 & 92 & 80 & 86 \\
\hline 120 & 87 & 7 & 92 & 13,0 & 92 & 7 & 92 & 90 & 90 \\
\hline 150 & 75 & 10 & 92 & 13,5 & 90 & 8 & 92 & 100 & 92 \\
\hline
\end{tabular}

В этой таблице и последующчих приведены усредненные данные шести опытов.

* Опыты проводили без перемешивания раствора, выдержка при заданной температуре - 5 мин.

Необходимость удаления углекислоты из анализируемых растворов обусловлена соосаждением хрома (YI) с карбонатами кальция и магния $[4,5]$. При воздействии УЗ углекислота полностью удаляется из анализируемых растворов во всем изученном диапазоне частот,

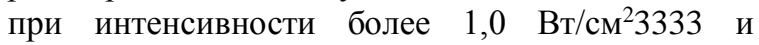
времени воздействия не ме нее 10 с (табл.2). Полноту удаления углекислоты контролировали титриметрически (табл.2) [4].

Таблица 2

Влияние параметров ультразвука на эффективность удаление углекислоты из растворов

\begin{tabular}{|c|c|c|c|c|c|}
\hline $\begin{array}{c}\text { Интен. У3, } \\
\text { Вт/см2 }\end{array}$ & $\begin{array}{c}\text { Степень } \\
\text { удаления, \% }\end{array}$ & $\begin{array}{c}\text { Частота У3, } \\
\mathbf{\kappa ц}\end{array}$ & $\begin{array}{c}\text { Степень } \\
\text { удаления, \% }\end{array}$ & $\begin{array}{c}\text { Время возд. } \\
\text { У3, с }\end{array}$ & $\begin{array}{c}\text { Степень } \\
\text { удаления, \% }\end{array}$ \\
\hline 0,5 & 91 & 15 & 98 & 5 & 90 \\
\hline 1,0 & 99 & 18 & 99 & 10 & 99 \\
\hline 1,5 & 99 & 22 & 99 & 15 & 99 \\
\hline 2,0 & 99 & 44 & 99 & 20 & 99 \\
\hline 2,5 & 99 & 47 & 99 & 25 & 99 \\
\hline
\end{tabular}

Для анализа использовался рассол Генического солезавода. Определение количества карбонатов проводили по [4].

Косвенно о полноте удаления углекислоты УЗ говорит факт отсутствия увеличения содержания хрома в осадке при ультразвуковом удалении углекислоты по сравнению с использованием кипячения(табл.2). При использовании УЗ затраты времени на процесс удаления углекислоты уменьшаются в 60 раз, а метрологические характеристики определения хрома не ухудшаются (табл.3).

Воздействие УЗ в момент осаждения осадка коллектора позволяет повысить степень соосаждения хрома(III) с 92 до $98-99 \%$ 


\begin{tabular}{|c|c|c|c|c|c|c|}
\hline Impact Factor: & $\begin{array}{l}\text { ISRA (India) } \\
\text { ISI (Dubai, UAE } \\
\text { GIF (Australia) } \\
\text { JIF }\end{array}$ & $\begin{array}{l}=1.344 \\
=0.829 \\
=0.564 \\
=1.500\end{array}$ & $\begin{array}{l}\text { SIS (USA) } \\
\text { PИНЦ (Russia) } \\
\text { ESJI (KZ) } \\
\text { SJIF (Morocco) }\end{array}$ & $\begin{array}{l}=0.912 \\
=0.207 \\
=4.102 \\
=\mathbf{2 . 0 3 1}\end{array}$ & $\begin{array}{l}\text { ICV (Poland) } \\
\text { PIF (India) } \\
\text { IBI (India) }\end{array}$ & $\begin{array}{l}=6.630 \\
=1.940 \\
=4.260\end{array}$ \\
\hline
\end{tabular}

(табл.4). Оптимальные параметры УЗ: частота 18-44 кГц, интенсивность 1,5-3,0 Вт/см², время воздействия более 30 с. При этом количество коллектора может быть уменьшено в 6 раз (табл.4). Кроме того, воздействие УЗ позволяет повысить эффективность концентрирования соосаждением, т.е. осуществлять процесс из более концентрированных растворов хлорида натрия (до 200 г/л), но степень соосаждения при этом уменьшается до 95\%, а количество коллектора не может быть уменьшено более 5 ммоль/л. Очевидно, что интенсифицирующим фактором воздействия УЗ на процесс концентрирования соосаждением является более высокая эффективность УЗ перемешивания по сравнению с механическим, а также диспергирование осадка, что приводит к увеличению его поверхности [10].

Таблица 3

Результаты определения хрома в водах, рассолах и поваренной соли

\begin{tabular}{|c|c|c|c|c|c|}
\hline \multirow[t]{3}{*}{$\begin{array}{c}\text { ОБЪЕКТ } \\
\text { АНАЛИЗА }\end{array}$} & \multirow{3}{*}{$\begin{array}{c}\text { Введено Cr } \\
\text { (III и YI), } \\
\text { мг/кг }\end{array}$} & \multicolumn{4}{|c|}{$\begin{array}{l}\text { Найдено Cr , мг/кг/относительное стандартное отклонение } \\
\qquad(\mathrm{p}=0,95, \mathrm{n}=6)\end{array}$} \\
\hline & & \multicolumn{2}{|c|}{ Предлагаемым методом } & \multicolumn{2}{|c|}{ Методом по [5] } \\
\hline & & $\mathrm{Cr}$ (III) & $\mathrm{Cr}(\mathrm{YI})$ & $\mathrm{Cr}(\mathrm{III})$ & $\operatorname{Cr}(\mathbf{Y I})$ \\
\hline \multirow{4}{*}{$\begin{array}{l}\text { Поваренная } \\
\text { соль } \\
\text { Тыретьский } \\
\text { солерудник } \\
\text { Россия }\end{array}$} & $0^{*}$ & $0,031 / 0,103$ & - & & \\
\hline & $0 * *$ & $0,033 / 0,094$ & - & & \\
\hline & $0 * * *$ & $0,033 / 0,092$ & - & $0,031 / 0,105$ & - \\
\hline & 0,05 & $0,084 / 0,082$ & $0,051 / 0,085$ & $0,078 / 0,100$ & $0,046 / 0,103$ \\
\hline \multirow{4}{*}{$\begin{array}{c}\text { Рассол, } \\
\text { Геческий } \\
\text { солепромысел } \\
\text { Украина }\end{array}$} & $0^{*}$ & $0,165 / 0,092$ & $0,047 / 0,103$ & & \\
\hline & $0 * *$ & $0,172 / 0,082$ & $0,052 / 0,088$ & & \\
\hline & $0 * * *$ & $0,176 / 0,078$ & $0,049 / 0,085$ & $0,168 / 0,090$ & $0,047 / 0,102$ \\
\hline & 0,05 & $0,224 / 0,076$ & $0,101 / 0,074$ & $0,209 / 0,087$ & $0,092 / 0,095$ \\
\hline \multirow{4}{*}{$\begin{array}{c}\text { Поваренная } \\
\text { соль, } \\
\text { Нахичеванский } \\
\text { солерудник } \\
\text { Азербайджан }\end{array}$} & $0 *$ & $0,54 / 0,036$ & $0,14 / 0,066$ & & \\
\hline & $0 * *$ & $0,54 / 0,036$ & $0,14 / 0,066$ & & \\
\hline & $0 * * *$ & $0,54 / 0,036$ & $0,14 / 0,066$ & $0,50 / 0,052$ & $0,11 / 0,075$ \\
\hline & 0,05 & $0,58 / 0,034$ & $0,18 / 0,064$ & $0,57 / 0,055$ & $0,18 / 0,072$ \\
\hline
\end{tabular}

* - УЗ использован только для удаления углекислоты, далее анализ проводился согласно [4].

* * - УЗ использован только для удаления углекислоты и для интенсификачии концентрирования соосаждением

Далее анализ проводился согласно [4].*** УЗ использован для удаления углекислоты, интенсификации концентрирования соосаждением и для окисления хрома (III) до хрома (YI).

Таблица 4

Влияние параметров ультразвука на степень соосаждения хрома(III) с гидроксидом магния

\begin{tabular}{|c|c|c|c|c|c|}
\hline $\begin{array}{c}\text { Интен. У3, } \\
\text { Вт/см2 }\end{array}$ & $\begin{array}{c}\text { Степень соо } \\
\text { саждения, \% }\end{array}$ & $\begin{array}{c}\text { Частота У3, } \\
\text { кГц }\end{array}$ & $\begin{array}{c}\text { Степень соо } \\
\text { саждения, \% }\end{array}$ & $\begin{array}{c}\text { Время возд. } \\
\text { У3, с }\end{array}$ & $\begin{array}{c}\text { Степень соо } \\
\text { саждения, \% }\end{array}$ \\
\hline 0,5 & 86 & 15 & 97 & 5 & 74 \\
\hline 1,2 & 90 & 18 & 98 & 10 & 89 \\
\hline 1,5 & 98 & 20 & 98 & 15 & 94 \\
\hline $2,0^{*}$ & 98 & 22 & 98 & 20 & 95 \\
\hline 2,0 & 99 & 28 & 98 & 25 & 96 \\
\hline 2,5 & 99 & 30 & 99 & 30 & 99 \\
\hline 3,0 & 98 & 34 & 99 & 35 & 99 \\
\hline 3,5 & 97 & 38 & 99 & 40 & 98 \\
\hline 4,0 & 96 & 44 & 99 & 45 & 98 \\
\hline 5,0 & 94 & 46 & 97 & 50 & \\
\hline $5,0 *$ & 97 & 47 & 96 & 50 & 98 \\
\hline
\end{tabular}


* - соосаждение проводилась с УЗ обработкой растворов насыщенных $\mathrm{N}_{2} \mathrm{O}$. Концентрация хлорида натрия 100 г/л. При изучении влияния интенсивности ультразвука остальные параметры были такими частота 44 кГц, время воздействия 35 с. При изучении влияния частоты ультразвука остальные параметры были такими - интенсивность 2,5 Bm/cм², время воздействия 35 с. При изучении влияния времени воздействия ультразвука остальные параметры были такими - частота 44 кГи, интенсивность $2,5 \mathrm{Bm} / \mathrm{cm}^{2}$.

Степень соосаждения хрома (III) с гидроксидом магния при проведении опытов в условиях постоянной $(20 \pm 1) 35^{\circ} \mathrm{C}$ и в условиях повышения температуры раствора (до $40{ }^{\circ} \mathrm{C}$ ), вызванное прохождением ультразуковых волн, составляет 98-99\%. Ведение процесса в условиях непрохождения звукохимических реакций, т.е. при насыщении пробы газом растворимым в воде, в частности $\mathrm{N}_{2} \mathrm{O}$ к увеличению степени соосаждения не приводит(табл.4) [9]. Следует отметить тот факт, что при увеличении интенсивности УЗ свыше 3 $\mathrm{B} / \mathrm{cm}^{2}$ степень соосаждения хрома(III) уменьшается(табл.4). Вероятно, это может быть вызвано увеличением растворимости гидроксида магния при повышении интенсивности УЗ, а возможно и структурными изменениями, происходящими в растворе и в гидроксиде магния при прохождении УЗ высокой интенсивности [4]. В пользу последнего предположения косвенно говорит факт некоторого увеличения степени соосаждения хрома при озвучивании раствора УЗ интенсивностью $5 \quad$ Вт/см ${ }^{2}$ в условиях непрохожения звукохимических реакций (табл.4).

Для окисления хрома(III) до хрома (VI) в анализируемых растворах воздействия одного УЗ в отсутствии введенных окислителей даже интенсивностью 15 Вт/см²3535 недостаточно (табл.5). При дополни- тельном введении окислителей: перекиси водорода, азотной кислоты и гипохлорита натрия происходит окисление хрома(III) до хрома (YІ) (табл.5). По условиям дальнейшего определения, лучшим является использование гипохлорита натрия [6]. Окисление хрома происходит во всем изученном диапазоне частот УЗ при интенсивности более 5 $\mathrm{B} / \mathrm{cm}^{2} 35$ и времени воздействия более 40 с. При использовании УЗ для интенсификации процесса окисления, количество вводимого гипохлорита натрия по сравнению с используемым в классическом методе может быть уменьшено в 20 раз, избыток гипохлорита натрия УЗ разрушается, а образовавшийся хлор удаляется. После обработки анализируемого раствора УЗ активный хлор йодометрическим методом не обнаружен [6]. О полноте разрушения остаточных количеств окислителя говорит факт хорошей устойчивости комплекса хрома(III) с дифенилкарбазидом (отсутствие заниженных результатов по сравнению с использованием метода по [5] (табл.3). Применение У3 для интенсификации окисления хрома позволяет уменьшить количество используемого гипохлорита натрия в 20 раз, сократить процесс окисления, разрушения гипохлорита натрия и удаления хлора в 70 раз, улучшить метрологические характеристики анализа (табл.3).

\section{Conclusion}

Таким образом, изучено использование УЗ для интенсификации пробоподготовки при спектрофотометрическом определении хрома в поваренной соли и рассолах: для удаления углекислоты из анализи- руемых растворов, для интенсификации концентрирования хрома(III) соосаждением, для окисления хрома (III) до хрома (VI). Разработана на методика определения хрома (III) и хрома (VI) в поваренной соли и рассолах. Предел обнаружения хрома при фотометрировании водных растворов дифенилкарбазида 0,012 мг/кг, при использовании экстракции комплекса хрома (VI) c дифенилкарбазидом в изоамиловый спирт - 0,0020 мг/кг. Правильность методики проверяли методом добавок на образцах поваренной соли и рассолов месторождений СНГ, а также анализом одних и тех же проб классическим спектрофотометрическим методом с дифенилкарбазидом [6] (табл. 3).

Таблица 5

Влияние действия различных окислителей на величи ну аналитического сигнала хрома при ультразвуковой интенсификации окисления хрома(III) до хрома (VI)

\begin{tabular}{|c|c|c|c|c|}
\hline \multirow[t]{2}{*}{$\begin{array}{c}\text { Введено } \\
\text { хрома(III), мг/кг }\end{array}$} & \multicolumn{4}{|c|}{$\begin{array}{c}\text { Используемый окислитель. } \\
\text { Найдено хрома(VI) мг/кг/Sr3535 (n=6; p=0,95) }\end{array}$} \\
\hline & H2O23535 & HNO33535** & NaCIO & Только УЗ* \\
\hline 0,020 & $\mathrm{O}, \mathrm{O} 20 / \mathrm{O}, \mathrm{O} 94$ & $\mathrm{O}, \mathrm{O} 18 / \mathrm{O}, 105$ & O,O20/O,O92 & - \\
\hline 0,050 & $\mathrm{O}, 049 / 0,089$ & $\mathrm{O}, \mathrm{O} 47 / \mathrm{O}, 093$ & $\mathrm{O}, 050 / \mathrm{O}, 087$ & - \\
\hline 0,100 & $\mathrm{O}, 095 / \mathrm{O}, 081$ & $\mathrm{O}, 092 / 0,093$ & $\mathrm{O}, 094 / \mathrm{O}, \mathrm{O} 79$ & - \\
\hline
\end{tabular}


Использовано воздействие УЗ частотой 44 кГи, интенсивностью $6 \mathrm{Bm} / \mathrm{cm}^{2}$ в течение $45 \mathrm{c}$. *-использовано воздействие УЗ частотой $44 \mathrm{\kappa} Г$ й, интенсивностью $15 \mathrm{Bm} / \mathrm{cm}^{2} 36 в$ течение $45 \mathrm{c}$. **. избыток окислителя удалялся нагреванием до прекращения выделения $\mathrm{NO}_{2}$.

Методика определения хрома (III) в поваренной соли и рассолах.

200,00 г поваренной соли растворяют в бидистиллированной воде и разбавляют до 1000 мл (или берут такое количество рассола, чтобы содержание хлорида натрия не превышало 200 г/л). Приливают 5 мл 1М раствора сульфата магния (если содержании магния в анализируемом растворе более 5 ммоль/л, то сульфат магния не прибавляют), подкисляют раствор 1 мл соляной кислотой плотностью 1,19

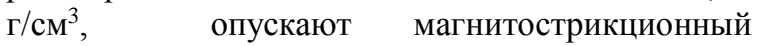
излучатель и воздействуют УЗ частотой 18-44 кГц, интенсивностью более $1 \mathrm{BT} / \mathrm{cm}^{2}$ в течение 15 c. для удаления углекислоты. К полученному раствору приливают 30 мл $10 \%$ раствора гидроксида натрия и воздействуют ультразвуком частотой 18-44 кГц, интенсивностью 1,5-3,0 Вт/см²36в течение 40 с. Дают осадку осесть. Прозрачный раствор сифонируют, затем к оставшемуся раствору приливают 500 мл дистиллированной воды и смесь интенсивно взбалтывают. Оставшуюся часть раствора отделяют от осадка центрифугированием. Осадок трижды промывают в центрифужной пробирке бидистиллированной водой, каждый раз взбалтывая смесь и центрифугируя. Растворяют осадок в 5 мл серной кислоты (1:5), ней трализуют $2 \%$ раствором гидроксида натрия, вводят 0,5 мл раствора гипохлорита натрия 2 г/л. Пробирку устанавливают в трубчатый магнитострикционный излучатель и воздействуют УЗ частотой 18-44 кГц, интенсивностью более $1,5 \mathrm{BT} / \mathrm{cm}^{2} 3636$ в течение
45 с. Полученный раствор переносят в мерную колбу вместимостью 50 мл, нейтрализуют раствором серной кислотой (1:5) до $\mathrm{pH} 6$ и приливают еще 1 мл серной кислоты (1:5), 0,5 мл $85 \%$ фосфорной кислоты, 2 мл $0,5 \%$ раствора дифенилкарбазида в ацетоне, доводят объем бидистиллированной водой до метки и перемешивают. Через 2 мин измеряют оптическую плотность полученного раствора на спектрофотометре при длине волны 535 нм в кюветах с толщиной поглощающего свет слоя 20 мм относительно раствора холостого опыта. При необходимости увеличения чувствительности определения, полученный раствор с центрифужной пробирки переносят в делительную воронку, нейтрализуют раствором серной кислотой (1:5) до $\mathrm{pH} 6$, приливают еще 1 мл серной кислоты (1:5), 0,5 мл $85 \%$ фосфорной кислоты, 2 мл 0,5\% раствора дифенилкарбазида в ацетоне и экстрагируют хром в течение 2 мин 5 мл изоамилового спирта. Оптическую плотность полученного раствора измеряют на спектрофотометре при длине волны 535 нм в кюветах с толщиной поглощающего свет слоя 10 мм относительно раствора холостого опыта.

Методика определения хрома (VI) в поваренной соли и рассолах.

Раствор, оставшийся после отделения хрома (III) соосаждением с гидроксидом магния, подкисляют серной кислотой до $\mathrm{pH} 2$ и кипятят 5 минут для восстановления хрома (VI)) до хрома (III). Полученный раствор нейтрализуют гидроксидом натрия и далее поступают так, как описано выше.

\section{References:}

1. Lur'ye, YU. YU. (1984) Analiticheskaya khimiya promyshlennykh stochnykh vod / YU. YU. Lur'ye . - M. : Khimiya, 1984. -p.448.

2. (2001) Sanitarno-epidemiologicheskiye pravila i normativy «Gigiyenicheskiye trebovaniya bezopasnosti i pishche-voy tsennosti pishchevykh produktov. SanPiN 2.3.2.107801», utverzhdennyye Glavnym gosudarstvennym sani-tarnym vrachom Rossiyskoy Federatsii 06.11.2001 g.
3. Baklanova LV, Belova EA, Baklanov AN (2018) IMPROVING THE SAFETY OF THE SALT. CONTENT DETERMINATION VARIOUS FORMS OF CHROM. ISJ Theoretical \& Applied Science, 04 (60): 43-49.

4. Petrenko P.A. (2018) Khimicheskiye laboratorii stran SNG. Spravochnik. Khar'kov: Solyanaya promyshlennost', 2018. -176p.

5. Baklanov A.N., Avdeyenko A.P., Chmilenko F.A., Baklanova L.V. (2011) Analiticheskaya 


\begin{tabular}{|c|c|c|c|c|c|c|}
\hline Impact Factor: & $\begin{array}{l}\text { ISRA (India) } \\
\text { ISI (Dubai, UAE } \\
\text { GIF (Australia) } \\
\text { JIF }\end{array}$ & $\begin{array}{l}=1.344 \\
=0.829 \\
=0.564 \\
=1.500\end{array}$ & $\begin{array}{l}\text { SIS (USA) } \\
\text { PИНЦ (Russia) } \\
\text { ESJI (KZ) } \\
\text { SJIF (Morocco) }\end{array}$ & $\begin{array}{l}=0.912 \\
=0.207 \\
=4.102 \\
=2.031\end{array}$ & $\begin{array}{l}\text { ICV (Poland) } \\
\text { PIF (India) } \\
\text { IBI (India) }\end{array}$ & $\begin{array}{l}=6.630 \\
=1.940 \\
=4.260\end{array}$ \\
\hline
\end{tabular}

khimiya povarennoy soli i rassolov. Kramatorsk: izd-vo DGMA, 2011. - 288 p.

6. Upor E., Makhai M., Novak D. (1985) Fotometricheskiye metody opredeleniya sledov neorganicheskikh soyedineniy. M. Mir, 1985. $359 \mathrm{p}$.

7. Yurchenko O.I., Baklanov A.N., Kalinenko O.C., Belova E.A., Baklanova L.V. (2016) Ultrasound in the determination of lead, copper and cadmiumin the sugar and products on its basis // International Scientific Journal Theoretical \& Applied Science. Section 9. Chemistry and chemical technology. - 2016. № 1 (33). - p. 158-163.

8. Goloperov IV, Belova EA, Baklanov AN (2016) ULTRASOUND IN THE
DETERMINATION CESIUM AND CESIUM137 IN HIGHLY WATERS, BRINE AND SALT. ISJ Theoretical \& Applied Science, 01 (33): 64-68.

9. Yurchenko O.I., Baklanov A.N., Kalinenko O.C., Belova E.A., Baklanova L.V. (2015) ULTRASOUND TO INTENSIFY OF FOOD DRY MINERALIZATION BY THE OXIDANTS IN VAPOR FORM // International Scientific Journal Theoretical \& Applied Science. Section 9. Chemistry and chemical technology. - 2015. - № 7 (27). - p. 122-129.

10. Margulis M.A. (1986) Zvukokhimicheskiye reaktsii i sonolyuminestsentsiya.-M.:Khimiya, 1986.-288 p. 